Marquette University

e-Publications@Marquette

School of Dentistry Faculty Research and

Publications

Dentistry, School of

$6-1-2002$

\title{
Mandible Cleft: Report of a Case and Review of the Literature
}

Luis Eduardo Almeida

Marquette University, luis.almeida@marquette.edu

Lucienne Ulbrich

Hospital Angelina Caron, Paraná, Brazil

Fabricio Togni

Hospital Angelina Caron, Paraná, Brazil

Accepted version. Journal of Oral and Maxillofacial Surgery, Vol. 60, No. 6 (June 2002): 681-684.

DOI. (C) 2002 Elsevier B.V. Used with permission.

Luis Eduardo Almeida was affiliated with Department of Oral and Maxillofacial Surgery, Dentofacial Deformities Center (CEDEFHAC), Hospital Angelina Caron, Paraná, Brazil at the time of publication. 
Marquette University

\title{
e-Publications@Marquette
}

\section{Dentistry Faculty Research and Publications/School of Dentistry}

This paper is NOT THE PUBLISHED VERSION; but the author's final, peer-reviewed manuscript.

The published version may be accessed by following the link in the citation below.

Journal of Oral and Maxillofacial Surgery, Vol. 60, No. 6 (2002): 681-684. DOI. This article is (C) Elsevier (WB Saunders) and permission has been granted for this version to appear in ePublications@Marquette. Elsevier (WB Saunders) does not grant permission for this article to be further copied/distributed or hosted elsewhere without the express permission from Elsevier (WB Saunders).

\section{Mandible Cleft: Report of a Case and Review of the Literature*}

\author{
Luis Eduardo Almeida \\ Department of Oral and Maxillofacial Deformities Center, Hospital Angelina Caron, Brazil \\ Marquette University School of Dentistry, Milwaukee, WI \\ Lucienne Ulbrich \\ Department of Oral and Maxillofacial Deformities Center, Hospital Angelina Caron, Brazil \\ Fabrício Togni \\ Department of Oral and Maxillofacial Deformities Center, Hospital Angelina Caron, Brazil
}

Median cleft of the lower lip and associated structures is a relatively rare condition. ${ }^{1}$ We report the case of a patient with mandibular cleft. Unlike other reported cases of similar disorders, there was no cleft of the lower lip. The literature on median clefts of the lower lip and mandible is reviewed, and the etiology and treatment are discussed.

\section{Report of a case}

A 10-year-old girl was referred to our unit at Angelina Caron Hospital on July 27, 1999. She was the first child of healthy parents. The patients gave no history of former abnormalities in the family. The 
pregnancy was uneventful, and as far as can be ascertained, there was no exposure of the mother to teratogenic substances during the pregnancy.

A general clinical examination revealed normal contour of the upper face and head (Figs 1, 2).

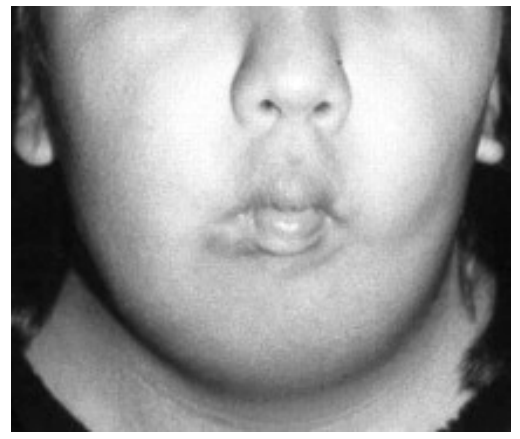

Fig. 1. Frontal view of the patient.

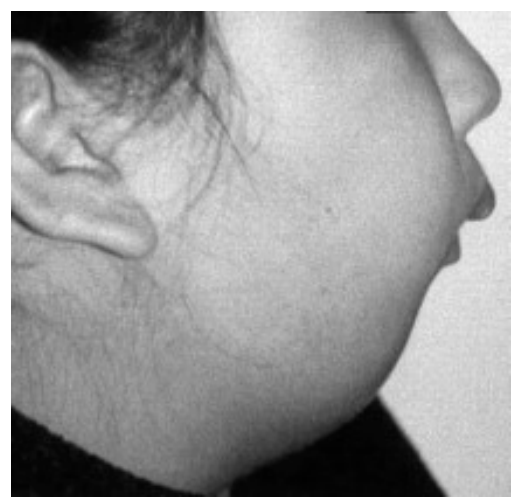

Fig. 2. Lateral view of the patient, showing the lack of chin prominence.

The upper and lower lips were intact, but there was a midline cleft of the mandible, and the 2 halves were freely movable. The morphology and size of the tongue were within normal limits, but the tip was bound with soft tissue overlying the midline (ankyloglossia). The lower incisors were not present at the time of the examination. In addition, there was evidence of other skeletal deformities: larger spaces among the fingers of the hands and the absence of chin prominence clinically and radiologically.

When asked to occlude, the patient, at a first trial, could occlude the left side. Then, when asked to clench hard, she could occlude the right side (Figs 3, 4)

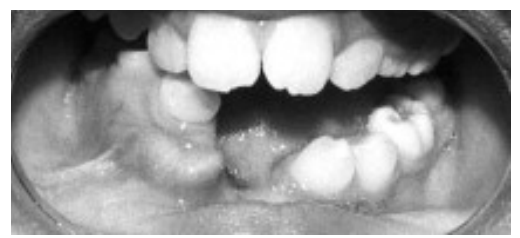

Fig. 3. Free movement of the fragments. 


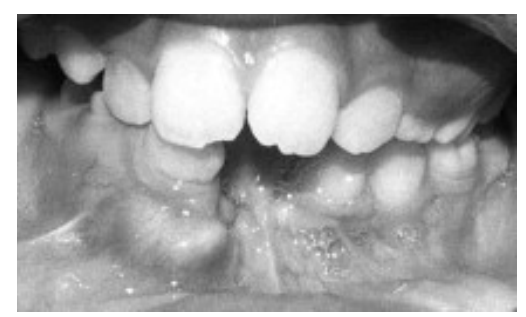

Fig. 4. Free movement of the fragments.

Radiographs confirmed the median cleft of the mandible. The mandibular left cuspid was in an abnormal position (Figs 5, 6).

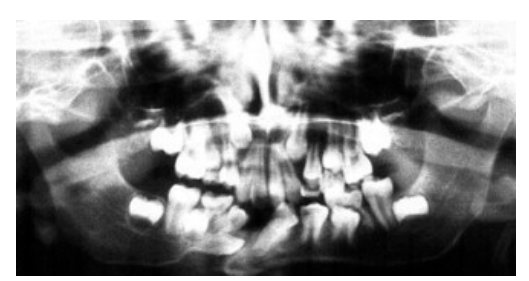

Fig. 5. Panoramic radiograph showing the mandible cleft and the absence of the inferior incisors.

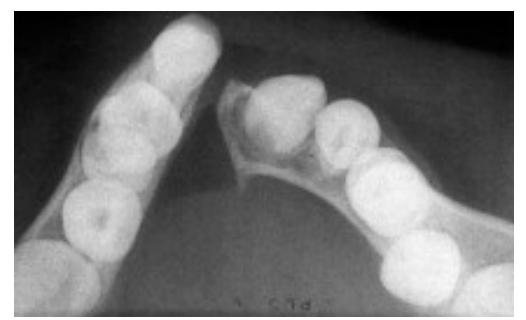

Fig. 6. Mandible occlusal radiograph showing the mandible cleft.

There also was agenesia of the lower incisors.

Correction of the soft and hard tissues was performed at the same time. With the patient under general anesthesia, the tongue was released with a Z-plasty, and a frenectomy of the lingual frenulum was performed (Fig 7).

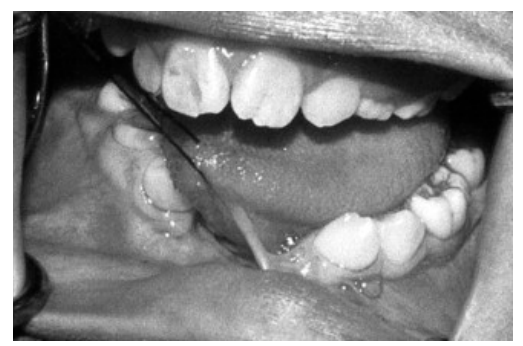

Fig. 7. Ankyloglossia of the patient.

After the frenectomy, an incision was made in the mandibular buccal sulcus between the cuspids, and a mucoperiosteal flap was raised. At the time of surgery, the left cuspid was extracted (Fig 8). 


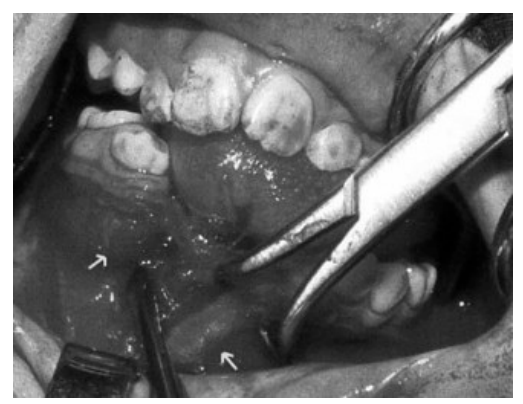

Fig. 8. After debridement, the 2 bone fragments could be observed independently (arrows).

Concerning correction of the bony defect, an autogenous iliac crest bone graft of $3 \mathrm{~cm}$ was planned. An occlusion as stable and functional as possible for the child's age was selected.

The bony defect was bridged with the autogenous iliac crest bone graft as described earlier. Rigid fixation was performed with 2 plates and 8 screws (Fig 9).

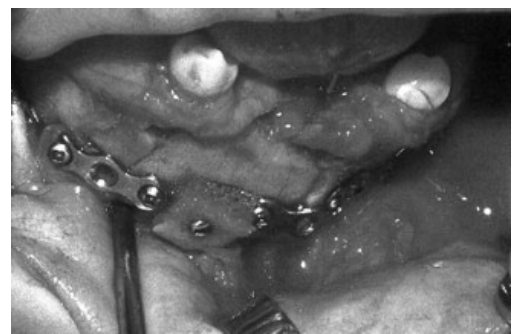

Fig. 9. Iliac crest graft positioned and fixed with plates and screws.

No intermaxillary fixation was used.

The postoperative course of the child was uneventful. After 6 months, the bone graft was well integrated with full union of the mandible. The tongue presents with normal movements. Occlusion is normal.

\section{Discussion}

This case is unusual because the patient had no cleft of the lower lip associated with a cleft mandible. Discussion of the etiology and treatment refers to both defects, and such are reported in the international literature. Monroe 2 reviewed the literature, and the first report he found was by Couronne in 1819.

Developmental anomalies of structures derived from the upper half of the first branchial arch are common, giving rise to deformities such as cleft lip or cleft palate. However, abnormal or incomplete development of structures derived from the lower half of the first branchial arch is rare. This may present as a complete ${ }^{3,4,5}$ or incomplete ${ }^{1,6,7,8,9,10}$ cleft of the lower lip, mandible,,$^{1,2,3,4,7,8,10,11,12}$ and tongue ${ }^{1,2,3,4,5,8,10,12}$ with occasional associated deformities of soft tissue structures in the neck derived from the lower branchial arch. ${ }^{12}$

Overall, there is a broad variation in the severity of this defect. ${ }^{11}$ The most common abnormalities related to this condition are congenital heart disease, ${ }^{2,3}$ absence of the hyoid bone, $\stackrel{2}{\text { and neck }}$ contracture. ${ }^{2,4,6}$ 
Facial clefts could be in general part of syndromes. However, in the presented case, we could not identify a specific syndrome.

Embryologically, the mandible develops from the cartilage of the first pharyngeal arch, the mandibular process, known as Meckel's cartilage. The mandible is derived from ossification of an osteogenic membrane formed from ectomesenchymal condensation at 36 to 38 days of development. In the mental region, on either side of the symphysis, 1 or 2 small cartilages appear, and endochondral ossification commences in the seventh month in utero to form a number of mental ossicles. These ossicles become incorporated into the intramembranous bone when the symphysis menti is converted from a syndesmosis to a synostosis during the first postnatal year. ${ }^{10}$

However, several hypotheses concerning the pathogenesis of this deformity have been proposed in the literature.

Most authors presume that failure of fusion of the mandible is probably due to a lack of mesodermal penetration into the midline structures of the mandibular portion of the first branchial arch. This failure may be a deficiency or delayed growth of the mesenchyme. Why this should occur so frequently in the upper lip and so seldom in the lower is an unanswered question. ${ }^{2,6,9}$ Also, considering the developmental stageof the organs involved, it appears that the disturbing influence occurs at the end of the fifth or at the beginning of the sixth week of gestation. ${ }^{6}$

In 1935, Morton and Jordon thought that the failure of the mandibular processes to fuse may keep the ventral ends of the succeeding arches from uniting in as much as fusion proceeds from above. ${ }^{8}$ This may explain the absence of the hyoid bone, thyroid cartilage, strap muscles, and manubrium in some of the more severe cases.

In 1981, Parnes et al-4 reported that the great variation in the severity of midline clefts of the lower lip and mandible and their association with other congenital defects, which are not necessarily related to branchial arch defects, suggest that these deformities are not hereditary but instead are produced by 1 or more localized influences that can cause the defect or defects. Thus, consideration should be given to the hypothesis that these deformities are caused by external factors that can result in widespread disturbances in embryologic development. ${ }^{4}$ This theory, however, can be easily excluded because of the fact that localization of the clefting deformity of the mandible involves the midline in all cases described. ${ }^{11}$

In 1995, however, Oostrom et $\mathrm{a}^{11}$ proposed a pathogenesis of clefts of the lip and mandible. Instead of paired branchial arches they reported that only 1 branchial arch develops during the early embryonic period, that is, the first 7 weeks of development, and that within this first branchial arch, 2 mandibular processes grow out, separated by a midline groove. Furthermore, they reported that the mandibular processes merge during the late embryonic period and that during the same period, the alveolar process and lip develop, together with the outgrowth of 1 membrane bone center in each mandibular process, resulting in the formation of the mandible with its symphysis. ${ }^{11}$

Therefore, hypoplasia of the mandibular process during the early embryonic period leads to the most severe cleft of the mandible, which extends into the neck, whereas during the late embryonic period, the less severe median clefts develop. Oostrom et al ${ }^{11}$ also proposed that disturbances of the outgrowth of bone centers of the mandible result in mandibular and soft tissue clefting, whereas defects in the 
merging process produce a notch of the vermilion or a higher cleft of the lower lip with or without involvement of the alveolar process of the mandible.

Concerning treatment, the rarity and variation of severity of the condition are responsible for the lack of a consensus on the nature and timing of the corrective surgery. The majority of the authors propose correction of the soft tissue structures as soon as possible, so as not to cause feeding and/or speaking problems, and mandibular bone grafting in later stages of life. The timing of treatment of mandibular clefts by most surgeons when the child is about 8 to 10 years to avoid damaging developing tooth buds. ${ }^{1,26,7,8,10,12}$ However, Sherman and Goulian ${ }^{3}$ described the successful management of a complete cleft of the lower lip and mandible in a 1-stage procedure in a 20-month-old child.

In our patient, we corrected both deformities in a 1-stage procedure in consideration of the age and the stage of development of the patient.

\section{References}

1 CC Knowles, AHM Littlewood, PG Bush. Incomplete median cleft of the lower lip and chin with complete cleft of the mandible. Br Dent J, 127 (1969), p. 337

$2 \mathrm{CW}$ Monroe. Midline cleft of the lower lip, mandible and tongue with flexion contracture of the neck: Case report and review of the literature. Plast Reconstr Surg, 38 (1966), p. 312

3 JE Sherman, D Goulian. The successful one-stage surgical management of a midline cleft of the lower lip, mandible and tongue. Plast Reconstr Surg, 66 (1980), p. 756

4 El Parnes, CN Galvão, Y Silva. Midline cleft of the lower lip and mandible: Report of a case. J Oral Surg, 39 (1981), p. 958

5 MM Chidzonga, JK Shija. Congenital median cleft of the lower lip, bifid tongue with ankyloglossia, cleft palate, and submental epidermoid cyst: Report of a case. J Oral Maxillofac Surg, 46 (1988), p. 809

$6 \mathrm{H}$ Fujino, Y Kyoshoin, T Katsuki. Median cleft of the lower lip, mandible, and tongue with midline cervical cord: A case report. Cleft Palate J, 7 (1970), p. 679

7 DR Millard, SA Wolfe, S Berkowitz. Median cleft of the lower lip and mandible: Correction of the mandibular defect. Br J Plast Surg, 32 (1979), p. 345

8 DR Millard, JA Lehman, M Deane, et al. Median cleft of the lower lip and mandible: A case report. $\mathrm{Br} J$ Plast Surg, 24 (1971), p. 391

9 R Ranta. Incomplete median cleft of the lower lip associated with cleft palate, the Pierre Robin anomaly or hypodontia. Int J Oral Surg, 13 (1984), p. 555

10 AP Armstrong, N Waterhouse. Tessier 30 median mandibular cleft: Case report and literature review. Br J Plast Surg, 49 (1996), p. 536

11CAM Oostrom, C Vermeij-Keers, PM Gilbert, et al. Median cleft of the lower lip and mandible. Case reports, a new embryologic hypothesis, and subdivision. Plast Reconstr Surg, 97 (1996), p. 313

12 MM Chidzonga, VM Lopez Perez, S Mzezewa. Treatment of median cleft of the lower lip, mandible, and bifid tongue with ankyloglossia: A case report. Int J Oral Maxillofac Surg, 25 (1996), p. 272 